\title{
Monitoring methotrexate-induced liver fibrosis in patients with psoriasis: utility of transient elastography
}

\author{
Harriet S Cheng' \\ Marius Rademaker ${ }^{2}$ \\ 'Dermatology Service, Auckland City \\ Hospital, Auckland, New Zealand; \\ ${ }^{2}$ Waikato Clinical Campus, Auckland \\ University Medical School, Hamilton, \\ New Zealand
}

This article was published in the following Dove Press journal: Psoriasis: Targets and Therapy

\begin{abstract}
Increasingly, existing evidence indicates that methotrexate-associated liver injury is related to comorbid risk factors such as diabetes, alcoholism, and obesity, rather than to methotrexate itself. Despite this fact, significant effort continues to be expended in the monitoring of low-dose methotrexate in patients with psoriasis. The gold standard investigation has been liver biopsy, but this is associated with significant morbidity and mortality. As methotrexate-induced liver injury is uncommon, the risk/benefit ratio of liver biopsy has been questioned. Fortunately, a number of new technologies have been developed for the diagnosis of chronic liver disease, including transient elastography (TE). TE is a type of shear wave ultrasound elastography, which measures the speed of shear waves used to estimate hepatic tissue stiffness. Several meta-analyses show very high pooled sensitivity and specificity for the diagnosis of hepatic cirrhosis $(87 \%$ and $91 \%$, respectively) in a variety of chronic liver disorders. It has a negative predictive value for cirrhosis of $>90 \%$ and a positive predictive value of $75 \%$. Recent European guidelines now advocate the use of TE as the first-line test for the assessment of fibrosis in alcohol- or hepatitisrelated liver disease, including nonalcoholic fatty liver disease (NAFLD). As the prevalence of obesity and metabolic syndrome, including NAFLD, is significantly elevated in patients with psoriasis, TE may be worth considering as a routine investigation for any patient with psoriasis. Although high-quality studies comparing TE with standard liver biopsy in the monitoring of psoriatics on low-dose methotrexate are lacking, the evidence from multiple small cohort studies and case series demonstrates its effectiveness. A recent Australasian position statement recommends that TE should be considered as a routine investigation for monitoring methotrexate therapy, repeated every 3 years if $\mathrm{kPa}<7.5$ and yearly if $\mathrm{kPa}>7.5$. Liver biopsy should be considered for patients with a $\mathrm{kPa}>9.5$.
\end{abstract}

Keywords: methotrexate, liver toxicity, transient elastography, FibroScan ${ }^{\circledR}$

\section{Introduction}

Despite its over 60 years of use, and the advent of biologic therapies, methotrexate remains an essential component of anti-psoriasis treatment, owing to its low expense, relatively low toxicity, and ready availability. ${ }^{1-4}$ The one ongoing concern is the potential for drug-induced liver injury (DILI), with the risk of hepatic fibrosis and cirrhosis initially thought to correlate with the cumulative dose of methotrexate. ${ }^{5,6}$ More recently, the risk of liver disease in patients with psoriasis has been related to comorbid risk factors such as diabetes, alcoholism, and obesity, rather than being methotrexate-induced. ${ }^{7}$ Obesity and consequent metabolic syndrome have become the leading causes of liver enzyme derangement worldwide due to associated nonalcoholic fatty liver disease
Correspondence: Marius Rademaker Tristram Clinic, 200 Collingwood Street, Hamilton 3204, New Zealand

Tel +6478381035

Email Rademaker@xtra.co.nz 
(NAFLD). NAFLD has a worldwide prevalence of $25 \%{ }^{8}$ and advances to nonalcoholic steatohepatitis (NASH) in $\sim 15 \%$ through progressive hepatocyte damage and fibrosis. ${ }^{9}$ Most current epidemiological studies of psoriasis demonstrate the significant prevalence of both obesity and metabolic syndrome in patients with psoriasis.

Liver biopsy has been the gold standard investigation for hepatic fibrosis, but it is invasive, with $1 \%$ of patients experiencing significant morbidity (eg, bleeding, pneumothorax, and shock) and a mortality rate of $0.01 \%-0.1 \%{ }^{10-12}$ Liver biopsy as a screening test is limited in 20\%-30\% of cases by both sampling error and interpathologist variation in interpretation. ${ }^{13,14}$ The procedure also carries a significant expense over other noninvasive tests. ${ }^{15}$ Given these factors, liver biopsy for the routine monitoring of patients with psoriasis varies considerably, ${ }^{16}$ with newer methods of monitoring, including biochemical markers and imaging, becoming commonplace (Figure 1). ${ }^{17}$

Transient elastography (TE) using FibroScan $®$ (Echosens $^{\mathrm{TM}}$, Paris, France) was first introduced in the early $2000 \mathrm{~s}$ as a noninvasive measure of liver fibrosis. ${ }^{18}$ It quickly gained popularity as an alternative to liver biopsy in patients with hepatitis $\mathrm{C}$ virus (HCV) and other chronic liver diseases. ${ }^{19}$ There is now significant interest in the clinical use of TE in monitoring of liver fibrosis in patients on methotrexate. This review examines the literature on the use of TE for monitoring methotrexate-associated liver fibrosis and discusses its utility in dermatological practice.

\section{Methotrexate-induced liver fibrosis}

Methotrexate inhibits dihydrofolate reductase, depleting stores of intracellular folate available for DNA and protein synthesis. At high doses, this results in reduced epidermal replication and has a potent effect on T-lymphocytes and macrophages. However, the therapeutic anti-inflammatory effects found with low doses $(<0.4 \mathrm{mg} / \mathrm{kg} /$ week $)$ are thought to be due to changes in adenosine signaling rather than folate metabolism. ${ }^{20}$ The inhibition of 5-aminoimidazole-4-carboxamide ribonucleotide formyltransferase by methotrexate leads to increased extracellular adenosine, which acts as a natural anti-inflammatory compound. ${ }^{21,22}$ Adenosine released in the liver in response to toxins (eg, ethanol, viruses, or drugs),

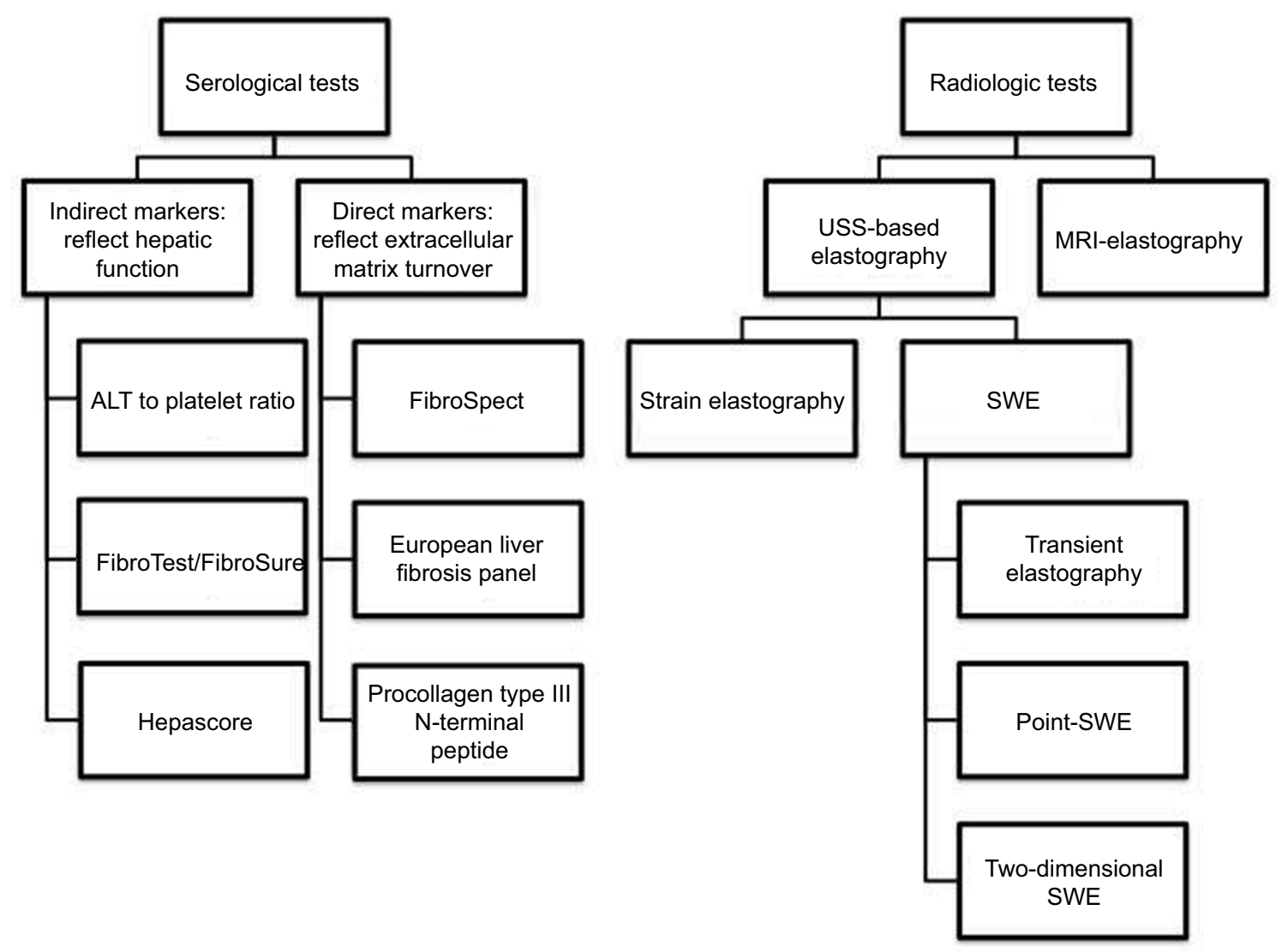

Figure I Examples of noninvasive modalities for the assessment of hepatic fibrosis.

Abbreviations: ALT, alanine aminotransferase; MRI, magnetic resonance imaging; SWE, shear wave elastography; USS, ultrasound scan. 
Table I Studies of liver biopsy in patients with psoriasis on methotrexate

\begin{tabular}{|c|c|c|c|c|}
\hline Study & Year & $\begin{array}{l}\text { Number of } \\
\text { patients }\end{array}$ & $\begin{array}{l}\text { Significant } \\
\text { fibrosis (\%) }\end{array}$ & Cirrhosis (\%) \\
\hline Reese et $\mathrm{a}^{169}$ & 1974 & 35 & 6 & 3 \\
\hline Zachariae et $\mathrm{al}^{70}$ & 1980 & 39 & - & 25.6 \\
\hline Robinson et $\mathrm{al}^{71}$ & 1980 & 43 & 25.6 & 0 \\
\hline Lanse et $\mathrm{al}^{72}$ & 1985 & 30 & 13 & 0 \\
\hline Mitchell et $\mathrm{al}^{73}$ & 1990 & 51 & 20 & 6 \\
\hline Themido et $\mathrm{al}^{74}$ & 1992 & 21 & 33.3 & 9.5 \\
\hline Van Dooren- & 1994 & 55 & 2 & 4 \\
\hline \multicolumn{5}{|l|}{ Greebe et $\mathrm{al}^{75}$} \\
\hline Boffa et $\mathrm{al}^{76}$ & 1995 & 49 & 22 & 0 \\
\hline Malatjalian et al ${ }^{77}$ & 1996 & 104 & 20 & 3 \\
\hline Zachariae et al ${ }^{78}$ & 2001 & 70 & 0 & 0 \\
\hline Aithal et $\mathrm{a}^{29}$ & 2004 & 66 & 4.5 & 0 \\
\hline Berends et $\mathrm{al}^{79}$ & 2006 & 125 & 4 & 2 \\
\hline Rosenberg et $\mathrm{al}^{37}$ & 2007 & 71 & 20 & 4 \\
\hline Lindsay et $\mathrm{al}^{45}$ & 2009 & 54 & 0 & 0 \\
\hline Bray et al ${ }^{64}$ & 2012 & 21 & 9.5 & 0 \\
\hline
\end{tabular}

however, promotes fibrosis, a form of sustained wound healing in response to injury through the upregulation of collagen production and suppression of metalloproteinases. ${ }^{23}$

Methotrexate is well recognized to cause asymptomatic elevation of hepatic transaminases in $15 \%-50 \%$ of patients on chronic low-dose therapy. These abnormalities are mild and self-limiting. ${ }^{24}$ Interestingly, supplementation with folate can reduce transaminase levels in patients taking methotrexate ${ }^{25-27}$ although the role of folate in preventing liver fibrosis is unclear.

The prevalence of significant hepatic fibrosis in patients taking methotrexate is estimated at 5\% (range: $0 \%-33 \%$ ) and cirrhosis at $1 \%-2 \%$ (range: $0 \%-26 \%$; Table 1 ). ${ }^{28,44}$ Aithal et al reviewed liver biopsies in 66 patients with psoriasis taking methotrexate. ${ }^{29}$ They found that the risk of significant fibrosis ranged from $0 \%$ in patients with a cumulative dose of $1.5 \mathrm{~g}$ to $8 \%$ in those with a cumulative dose of $6 \mathrm{~g}$, but failed to show statistical correlation as the numbers were low. A meta-analysis of 636 patients on methotrexate from 15 studies did not show a correlation between cirrhosis and cumulative dose, but it did show an increased risk of hepatic fibrosis in patients who drank $\geq 100 \mathrm{~g}$ alcohol/week (17.8\% vs $4.5 \%$ ) and who had psoriasis versus rheumatoid arthritis (7.7\% vs $2.7 \%)$.

A recent Dutch population-based study of 1,535 individuals, of whom 74 had psoriasis, showed that $8.1 \%$ of psoriatics had advanced liver fibrosis compared with 3.6\% of nonpsoriatics, even after adjustment for demographics, lifestyle characteristics, and laboratory findings (odds ratio
[OR]: 2.57; 95\% confidence interval [CI]: $1.0-6.6) .{ }^{30}$ However, a meta-analysis showed that methotrexate was associated with an increased risk of liver fibrosis compared with psoriasis patients not treated with methotrexate, with a pooled risk difference of 0.22 (95\% CI: 0.04-0.41). ${ }^{31} \mathrm{~A}$ significant confounder of methotrexate and liver disease reports, though, is that methotrexate is given to patients with more severe psoriasis, making it difficult to tease out the cause and effect of drug versus disease severity.

Histologically, methotrexate-induced liver damage demonstrates steatosis, Ito cell hypertrophy, nuclear pleomorphism, and portal fibrosis. The Roenigk pathological grading of hepatic fibrosis in patients with psoriasis treated with methotrexate ${ }^{32}$ has been shown to be a reliable and clinically useful indicator of methotrexate-induced liver damage (grade F0/F1 - normal, F2 - no fibrosis but moderate or severe fatty changes, F3 - moderate or severe fibrosis, and F4 - cirrhosis), ${ }^{33}$ although this classification system is relatively conservative compared with other staging systems.

Patients with methotrexate-associated liver disease have very similar risk factors to NASH, including type 2 diabetes mellitus and obesity (Figure 2). ${ }^{34}$ In addition, NASH itself is a significant cause of liver injury in patients with psoriasis on

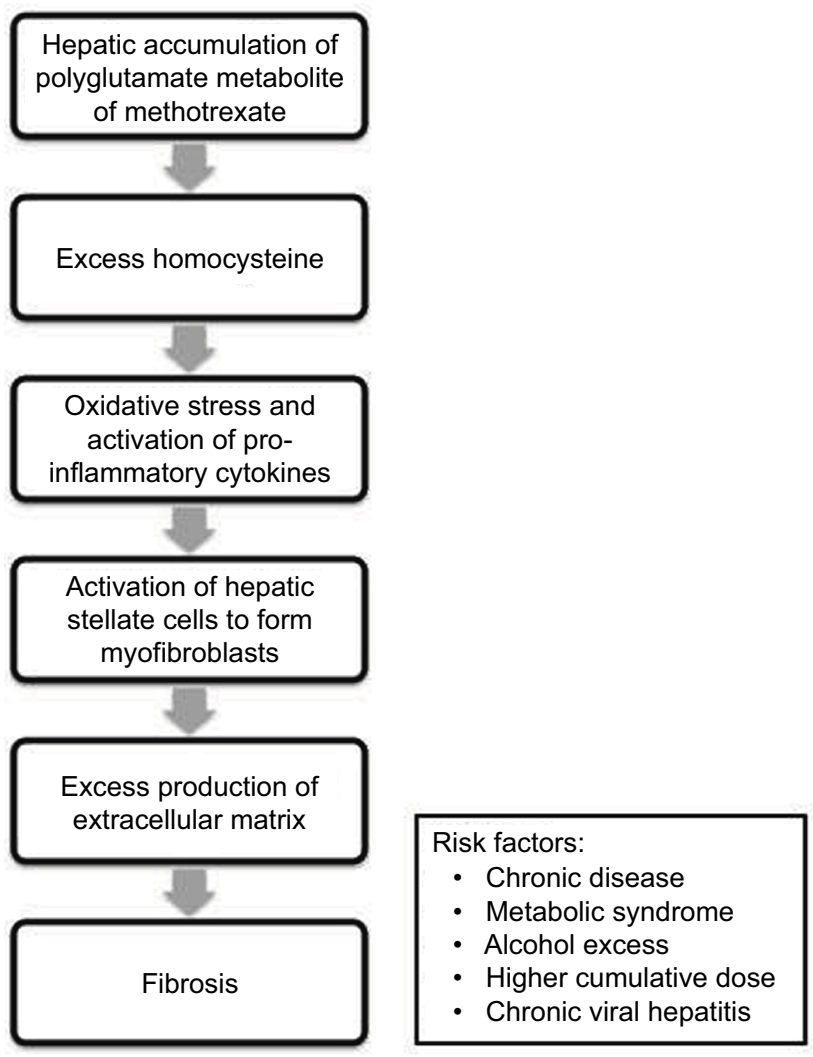

Figure 2 Pathogenesis of methotrexate-induced hepatic fibrosis. 
methotrexate, ${ }^{35,36}$ which may occur at lower cumulative doses of methotrexate ${ }^{37}$ Overall, the literature suggests a cumulative effect of steatosis, alcohol, obesity, and DILI in the etiology of liver fibrosis in patients with psoriasis on methotrexate.

\section{Current monitoring guidelines for methotrexate-induced liver fibrosis}

Various guidelines for the use of methotrexate in psoriasis have been published..$^{32,38-43}$ The 2009 American guidelines stratify patients into low or high risk based on risk factors (eg, metabolic syndrome, alcohol consumptions, and pre-existing liver disease). ${ }^{39}$ No baseline liver biopsy is advised for lowrisk patients. For this group, liver biopsy can be considered at a cumulative dose of 3.5-4.0 g, or alternative options include continuous monitoring of liver biochemistry or switching to an alternative systemic agent. For high-risk patients, a delayed baseline biopsy can be considered and should be repeated after a cumulative dose of 1.0-1.5 g. Noninvasive monitoring such as TE is not discussed.

The 2016 British guidelines advocate baseline testing of procollagen type III N-terminal peptide (P3NP) along with routine liver biochemistry. ${ }^{40} \mathrm{P} 3 \mathrm{NP}$ is released and cleaved during collagen synthesis. ${ }^{44}$ It is a nonspecific marker of fibrosis and is less useful in patients with psoriatic arthritis due to inflammation leading to persistent elevation, as well as in younger ( $<20$ years) and older ( $>70$ years) patients. ${ }^{45}$ It is suggested that this test can be used as a screening tool; patients with P3NP $>8 \mathrm{mg} / \mathrm{mL}$ require further liver evaluation. P3NP can also be used as a monitoring tool by being repeated every 3 months. The pooled sensitivity for P3NP was 0.74 , with a pooled specificity of 0.77 giving a pooled positive likelihood ratio of 5.32, and a pooled negative ratio of 0.35. ${ }^{80}$ However, the low incidence of methotrexate-induced liver fibrosis makes the economics of this testing debatable. The British methotrexate guidelines do not recommend the routine use of liver biopsy. TE is discussed, but the authors comment that its use has not yet validated in the specific population of methotrexate-treated patients with psoriasis.

A 2017 Australasian recommendation based on expert opinion and literature review discusses the negative riskbenefit ratio of routine liver biopsy for monitoring methotrexate-related liver fibrosis and explores alternate forms of monitoring. ${ }^{17}$ The authors note that, in current practice, significant DILI from methotrexate is quite rare, and the majority of deaths in patients with psoriasis, who have advanced liver disease, is from cardiovascular events, rather than from liver failure. This consensus statement suggests that baseline TE be considered and repeated every $1-3$ years.

\section{TE}

TE is a type of shear wave ultrasound elastography, which measures the speed of shear waves used to estimate hepatic tissue stiffness. ${ }^{18}$ An ultrasound transducer is mounted on a vibrator that transmits a low-frequency $(50 \mathrm{~Hz})$ vibration to create an elastic shear wave that travels through the tissue. The transducer measures the velocity of the shear wave, which is used to calculate tissue stiffness. The result is expressed in $\mathrm{kPa}$ and ranges from 1.5 to $75 \mathrm{kPa}$ with normal values around $5 \mathrm{kPa}$, higher in men and in patients with low or high body mass index (BMI; a U-shaped distribution). ${ }^{46}$ The test is repeated with the final result being the median of 10 successful measurements. At least $60 \%$ of attempted readings should be successful, and the interquartile range of repeated measurements should not exceed $30 \%$ of the median; otherwise, the test is considered invalid. ${ }^{47} \mathrm{~A}$ TE measurement of $>7 \mathrm{kPa}$ is suggestive of advanced fibrosis in most chronic liver disorders; there is some variation in the cutoffs for diagnosing cirrhosis, with optimal thresholds being $>10 \mathrm{kPa}$ for NAFLD and $>12.5$ for $\mathrm{HCV}^{48}$

The transducer is positioned over the right 9th, 10th, or 11 th intercostal space to measure the elasticity of the right lobe of the liver (Figure 3). Sampling error can be reduced by varying the position of the transducer. ${ }^{49}$ However, it is important to note that the final measurement does not represent the entirety of hepatic tissue. The presence of ascites and significant adipose tissue interferes with shear wave propagation, and these are important limitations of TE. In a prospective study of more than 2,000 liver stiffness measurements, TE had a failure rate of $4.5 \% .{ }^{50}$ In multivariate analysis, increased BMI was the only factor positively associated with failure (although this study excluded patients with

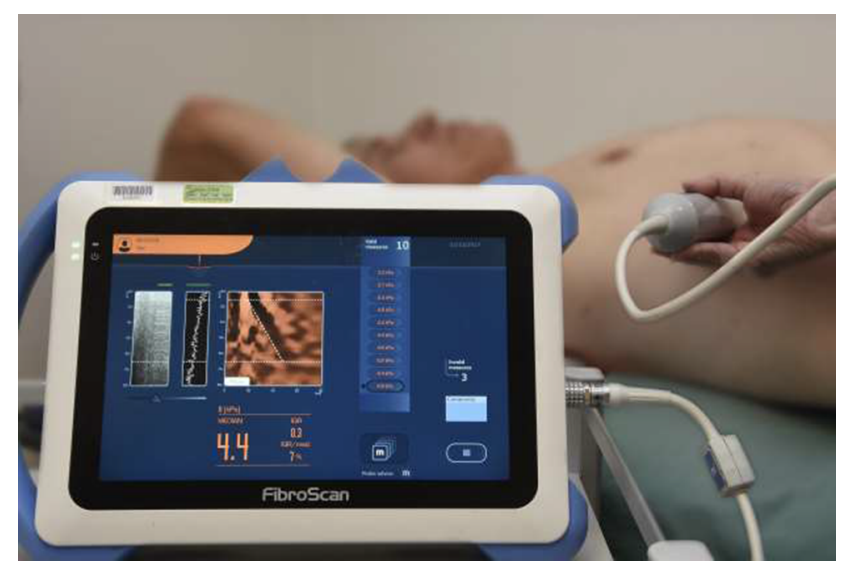

Figure 3 A patient undergoing TE using FibroScan 430 mini (Echosens, Paris, France). TE median of 10 measurements $-4.4 \mathrm{kPa}, \mathrm{IQR}=0.3$. Abbreviations: IQR, interquartile range; TE, transient elastography. 
ascites). In another large TE series of 13,369 examinations, the failure rate was $3.1 \%$, with suboptimal results being found in $15.8 \%$, mostly due to obesity. ${ }^{51}$

FibroScan has low interobserver variability and is easily performed in the outpatient clinic, making it ideal for screening or periodic monitoring. However, it cannot determine the etiology of any fibrosis/cirrhosis; therefore, liver biopsy or other liver-specific investigations may be required.

\section{Performance of TE in the diagnosis of liver fibrosis of any cause}

There is strong, high-quality evidence to support the use of $\mathrm{TE}$ as a noninvasive measure of liver fibrosis. A 2007 metaanalysis of nine studies comparing the diagnostic accuracy of TE with liver biopsy in patients with liver fibrosis due to various causes (but predominantly chronic HCV infection) found a pooled sensitivity and specificity for hepatic cirrhosis of $87 \%$ and $91 \%$, respectively. ${ }^{52}$ The analysis showed a large positive likelihood ratio of 11.7 (95\% CI: 7.9-17.1), indicating that $\mathrm{TE}$ can provide strong diagnostic evidence for hepatic cirrhosis. A meta-analysis by Adebajo et al also found a large positive likelihood ratio of seven for TE in the diagnosis of cirrhosis in patients with recurrent $\mathrm{HCV}$ infection after liver transplantation. ${ }^{53}$ The pooled positive likelihood ratio for the diagnosis of fibrosis was 4.95 (95\% CI: 3.4-7.2). Overall, there is some heterogenicity in specificities (range: $65 \%-98 \%$, pooled specificity $84 \%$ ) for the diagnosis of cirrhosis using TE, whereas sensitivity outcomes were more consistent (range: 93\%-100\%; pooled sensitivity: 98\%). TE has a negative predictive value for cirrhosis of $>90 \%$ and a positive predictive value of $75 \%{ }^{46}$ and is better for the detection of cirrhosis than for the detection of significant fibrosis.

A Cochrane review examined TE for the diagnosis of liver fibrosis in patients with alcoholic liver disease. ${ }^{54}$ This study excluded patients with other causes of liver disease, including drug-induced hepatotoxicity. The authors comment on the variability of TE cutoff values for identifying stages of fibrosis, and the values used for analysis were based on those most frequently used in studies: $7.5 \mathrm{kPa}$ - significant fibrosis (F2) or worse, $9.5 \mathrm{kPa}$ - severe fibrosis (F3) or worse, and $12.5 \mathrm{kPa}$ - cirrhosis or advanced scarring (F4). The authors advise caution in using these cutoff values, given limited available evidence. For the diagnosis of significant fibrosis (F2) or worse, the pooled positive and negative likelihood ratios were 8.2 and 0.07 , respectively.

The accuracy of TE is best when it is negative (ie, $<7.5$ $\mathrm{kPa}$ ), as severe fibrosis or cirrhosis can then be excluded. However, while liver stiffness measurement on TE has been correlated with fibrosis stage, ${ }^{50}$ diagnostic accuracy is reduced for lesser stages of fibrosis. ${ }^{55}$

Recent European guidelines now advocate the use of FibroScan as the first-line test for the assessment of fibrosis in alcohol- or hepatitis-related liver disease. ${ }^{46,56,57}$ They suggest prescreening with a biomarker, such as the enhanced liver fibrosis test, to select patients who should proceed to FibroScan. They also recommend that patients with significant fibrosis should be screened using TE every 2-3 years to monitor for progression toward cirrhosis.

\section{TE and psoriasis}

TE has been used to investigate liver disease in patients with psoriasis. The Rotterdam study investigated 74 psoriatics not on systemic therapy and, using a cutoff TE of $>9.5 \mathrm{kPa}$, demonstrated severe fibrosis in $8.1 \%$ of patients compared with $3.6 \%$ of 1461 nonpsoriatic controls (OR: 2.57; 95\% CI: $1.0-6.6) .{ }^{30}$

\section{TE and methotrexate}

There are limited high-quality data of the performance of TE in monitoring methotrexate in patients with Crohn's disease, rheumatoid arthritis, or psoriasis. A study on patients with Crohn's disease showed similar median TE scores for those who had received $>1500 \mathrm{mg}$ methotrexate $(\mathrm{n}=21$, $5.5 \mathrm{kPa})$ to methotrexate-naïve patients $(\mathrm{n}=33,4.5 \mathrm{kPa}) .{ }^{58}$ Two methotrexate patients had abnormal TE scores; liver biopsy showed Roenigk grade 2 changes with significant steatosis of NAFLD (TE score: $9.2 \mathrm{kPa}$; BMI: $38 \mathrm{~kg} / \mathrm{m}^{2}$ ) and Roenigk grade 4 with cirrhosis (TE score: $24.5 \mathrm{kPa}$ ), attributed to methotrexate.

In a further study of 46 patients with inflammatory bowel disease treated with a mean cumulative dose of $1.2 \pm 1.3 \mathrm{~g}$ of methotrexate, the TE was $4.7 \pm 6.9 \mathrm{kPa}$. Using cutoffs of 7.1 $(\mathrm{F} \geq 2), 9.5(\mathrm{~F} \geq 3)$, and $12.5 \mathrm{kPa}(\mathrm{F} \geq 4)$, there were 35 patients (76.1\%) with grade F0/1, eight patients $(17.4 \%)$ with F2, and three patients $(6.5 \%)$ with $\mathrm{F} \geq 3$. There were no differences in liver stiffness depending on sex, age, type of inflammatory bowel disease, or cumulative dose of methotrexate. Three patients with grade $\mathrm{F} \geq 3$ had comorbidities of long-term alcohol abuse, obesity (BMI: $38.9 \mathrm{~kg} / \mathrm{m}^{2}$ ), or polypharmacy. The study was limited by no confirmation with liver biopsies. ${ }^{59}$

In a study of FibroScan in 518 patients (Crohn's disease, 124; rheumatoid arthritis, 149; psoriasis, 111), 390 patients were being treated with methotrexate. ${ }^{60}$ Using a cutoff of TE $>7.9 \mathrm{kPa}, 8.5 \%$ (44) patients were considered to have severe fibrosis. Ten of these patients underwent liver biopsy, eight had features of NASH, two had alcoholic liver damage, one 
had hemochromatosis, and the remaining two had chronic liver lesions associated with mild fibrosis. In a multivariate analysis, factors associated with liver fibrosis were the BMI $>28 \mathrm{~kg} / \mathrm{m}^{2}$ and high alcohol consumption, but not the duration of methotrexate nor cumulative dose.

An early study of 24 psoriasis patients on methotrexate used FibroTest (six biochemical markers) and TE in those who had undergone routine liver biopsy within the previous 18 months. ${ }^{61}$ Four patients failed TE due to obesity (17\%), but in the remaining 20 patients, TE ranged from 3.3 to $18.4 \mathrm{kPa}$. TE had good negative predictive value and correctly identified $88 \%$ of those without significant fibrosis. Limitations of this study included retrospective design, operators performing TE not blinded to liver biopsy findings, and the potential for interval change from biopsy to TE and low numbers (only six patients had significant fibrosis).

The high failure rate of TE due to obesity in patients with psoriasis (17\%) is echoed in further studies. A New Zealand study found a failure rate of $25 \%$ in 133 patients on methotrexate for dermatological disorders despite the use of the XL probe designed for use in obese patients. ${ }^{62}$ Other reported failure rates ranged from $1.8 \%$ (Thailand) to $52 \%$ (UK). ${ }^{63,64}$

The sensitivity of TE in methotrexate-treated psoriasis patients is high. A sensitivity of $100 \%$ with a $67 \%$ specificity was found in one study of 10 patients with valid TE measurements; the median lag time between TE and liver biopsy was 61 days. ${ }^{64}$ There were three false positives on TE, but no false negatives. In a systematic review the pooled sensitivity for P3NP, fibroscan, ultrasound and radionuclide scintigraphy was $0.74,0.60,0.55$ and 0.60 respectively. The pooled specificity was $0.77,0.80,0.49$ and 0.77 , giving a respective pooled positive likelihood ratio of 5.32, 2.65, 0.81 and 2.51 for P3NP, fibroscan, ultrasound and radionuclide scintigraphy. ${ }^{80}$

In a study of Asian patients with psoriasis, 10 of 41 patients had methotrexate-associated liver injury (Roenigk grade $\geq 3$ ) with two of them having significant liver fibrosis (METAVIR fibrosis stage $\geq 2$ ) diagnosed by liver biopsy. Using a cutoff TE of $7.1 \mathrm{kPa}$, the sensitivity was $50 \%$ and the specificity was $83.9 \%$ for detecting methotrexate-associated liver injury; for identifying significant liver fibrosis, the sensitivity was $50 \%$ and specificity was $76.9 \% .{ }^{65}$

Lynch et al reported TE findings in 77 patients with psoriasis on methotrexate. ${ }^{66}$ Five had liver biopsy, of whom two had significant fibrosis. One of these had abnormal TE, and the other had an invalid scan. The remaining three without fibrosis had normal TE. In this study, abnormal findings on TE were associated with obesity rather than cumulative methotrexate dose, but the low proportion of patients having liver biopsy makes it difficult to draw any conclusion.

A Swedish study compared patients with psoriasis on methotrexate (divided into groups based on treatment duration $<2$ or $\geq 2$ years) with a control group of patients with psoriasis on biologics. ${ }^{67}$ Two hundred and one patients underwent TE and biochemical tests including liver biochemistry, platelet count, and P3NP. There was no significant difference in liver stiffness measurements on TE between the groups. Fourteen had TE showing advanced fibrosis; only four of them had elevated P3NP. Just over half ( 8 of 14) of patients with abnormal TE went on to liver biopsy; six had advanced fibrosis and two had mild fibrosis. Only patients with abnormal TE had liver biopsy; therefore, a false-negative rate for TE could not be calculated.

A New Zealand study found that $80 \%$ of 100 patients on methotrexate (mostly for psoriasis) had normal TE, 13\% had mild fibrosis, 3\% had moderate fibrosis, and $2 \%$ had severe fibrosis/cirrhosis. ${ }^{62}$ Only one patient, with a $\mathrm{kPa}$ of 14.3, suggestive of severe fibrosis (F4), went on to have liver biopsy; this showed features of fibrosis consistent with methotrexate-associated injury.

Unfortunately, high-quality studies of sequential TE measurement in psoriatic patients, backed up with liver biopsy and adjusted for confounding factors, remain to be performed.

\section{Recommendations}

As patients with psoriasis, particularly those with comobidities of obesity, diabetes, and metabolic syndrome, are at an increased risk of developing NAFLD, it may be beneficial to consider a baseline TE, even if methotrexate is not being considered. Early evidence suggests that clinical response to systemic therapies, including anti-tumor necrosis factor biologics, is reduced in patient with obesity, metabolic syndrome, and fatty liver. If there is evidence of liver fibrosis on TE, strategies to help to modify lifestyle should be strongly encouraged.

For patients starting on methotrexate, consider a baseline TE within the first 6 months of starting methotrexate and, if $\mathrm{TE}<7.5 \mathrm{kPa}$, repeat every 3 years. If the $\mathrm{kPa}$ is in the range of 7.5-9.5, consider repeating the test in 1 year and consider a referral to a hepatologist. If the TE is $\geq 9.5$ $\mathrm{kPa}$, liver biopsy or other liver-specific investigations may be appropriate. 


\section{Conclusion}

Ideally, a noninvasive test of liver fibrosis should be "specific to the liver, be easy-to-perform in any laboratory, reflects the stage of fibrosis, be cost-effective, and be reproducible between laboratories, and the results should be independent of any associated inflammation". ${ }^{68}$ None of the available tests fulfill all of these criteria; therefore, monitoring should be tailored to the individual patient and their comorbidities. At present, a combination of testing methods is the optimal approach, using biochemistry, TE, and when appropriate liver biopsy. The utility of TE in patients with psoriasis is twofold: 1) in the investigation of NAFLD- or NASH- associated fibrosis, whether on methotrexate or not, and 2) in the monitoring of methotrexate therapy. However, both are partly limited by the relatively high failure rate of the test due to obesity.

While TE has largely replaced liver biopsy as the diagnostic test for liver fibrosis in many clinical settings, available studies on methotrexate-treated psoriasis patients remain limited. However, it is unlikely that large high-quality studies will be conducted, as methotrexate-induced liver injury is uncommon. Evidence must therefore be generalized from studies with less targeted populations, which indicates that $\mathrm{TE}$ will be a valuable test in the monitoring of patients with psoriasis.

\section{Acknowledgment}

We are very grateful to Marice Morrison, Senior Dermatology Nurse, Waikato Hospital, Hamilton, New Zealand.

\section{Disclosure}

The authors report no conflicts of interest in this work.

\section{References}

1. Gubner R, August S, Ginsberg V. Therapeutic suppression of tissue reactivity. II. Effect of aminopterin in rheumatoid arthritis and psoriasis. Am J Med Sci. 1951;221(2):176-182.

2. Hunter GA. The use of methotrexate in the treatment of psoriasis. Austr J Dermatol. 1962;6:248-254.

3. Edmundson WF, Guy WB. Treatment of psoriasis with folic acid antagonists. AMA Arch Dermatol. 1958;78(2):200-203.

4. Warren RB, Chalmers RJ, Griffiths CE, Menter A. Methotrexate for psoriasis in the era of biological therapy. Clin Exp Dermatol. 2008;33(5):551-554.

5. Dahl MG. Methotrexate and the liver. Br JDermatol. 1969;81(6):465-467.

6. Carneiro SC, Cassia FF, Lamy F, Chagas VL, Ramos-e-Silva M. Methotrexate and liver function: a study of 13 psoriasis cases treated with different cumulative dosages. J Eur Acad Dermatol Venereol. 2008;22(1):25-29.

7. Rodriguez-Zuniga MJM, Garcia-Perdomo HA. Systematic review and meta-analysis of the association between psoriasis and metabolic syndrome. J Am Acad Dermatol. 2017;77(4):657-666.e658.

8. Younossi ZM, Koenig AB, Abdelatif D, Fazel Y, Henry L, Wymer M. Global epidemiology of nonalcoholic fatty liver disease-meta-analytic assessment of prevalence, incidence, and outcomes. Hepatology. 2016;64(1):73-84
9. Vernon G, Baranova A, Younossi ZM. Systematic review: the epidemiology and natural history of non-alcoholic fatty liver disease and non-alcoholic steatohepatitis in adults. Aliment Pharmacol Ther. 2011;34(3):274-285.

10. Mueller M, Kratzer W, Oeztuerk S, et al. Percutaneous ultrasonographically guided liver punctures: an analysis of 1961 patients over a period of ten years. BMC Gastroenterol. 2012;12:173.

11. West J, Card TR. Reduced mortality rates following elective percutaneous liver biopsies. Gastroenterology. 2010;139(4):1230-1237.

12. Howlett DC, Drinkwater KJ, Lawrence D, Barter S, Nicholson T. Findings of the UK national audit evaluating image-guided or image-assisted liver biopsy. Part II. Minor and major complications and procedurerelated mortality. Radiology. 2013;266(1):226-235.

13. Maharaj B, Maharaj RJ, Leary WP, et al. Sampling variability and its influence on the diagnostic yield of percutaneous needle biopsy of the liver. Lancet. 1986;1(8480):523-525.

14. Campbell MS, Reddy KR. Review article: the evolving role of liver biopsy. Aliment Pharmacol Ther. 2004;20(3):249-259.

15. Crossan C, Tsochatzis EA, Longworth L, et al. Cost-effectiveness of non-invasive methods for assessment and monitoring of liver fibrosis and cirrhosis in patients with chronic liver disease: systematic review and economic evaluation. Health Technol Assess. 2015;19(9):1-409, v-vi.

16. Collin B, Srinathan SK, Finch TM. Methotrexate: prescribing and monitoring practices among the consultant membership of the British Association of Dermatologists. Br J Dermatol. 2008;158(4): 793-800.

17. Rademaker M, Gupta M, Andrews M, et al. The Australasian Psoriasis Collaboration view on methotrexate for psoriasis in the Australasian setting. Australas J Dermatol. 2017;58(3):166-170.

18. Sandrin L, Fourquet B, Hasquenoph JM, et al. Transient elastography: a new noninvasive method for assessment of hepatic fibrosis. Ultrasound Med Biol. 2003;29(12):1705-1713.

19. Castéra L, Vergniol J, Foucher J, et al. Prospective comparison of transient elastography, Fibrotest, APRI, and liver biopsy for the assessment of fibrosis in chronic hepatitis C. Gastroenterology. 2005;128(2):343-350.

20. Brown PM, Pratt AG, Isaacs JD. Mechanism of action of methotrexate in rheumatoid arthritis, and the search for biomarkers. Nat Rev Rheumatol. 2016;12(12):731-742.

21. Baggott JE, Vaughn WH, Hudson BB. Inhibition of 5-aminoimidazole4-carboxamide ribotide transformylase, adenosine deaminase and 5 '-adenylate deaminase by polyglutamates of methotrexate and oxidized folates and by 5 -aminoimidazole-4-carboxamide riboside and ribotide. Biochem J. 1986;236(1):193-200.

22. Cronstein BN, Kramer SB, Weissmann G, Hirschhorn R. Adenosine: a physiological modulator of superoxide anion generation by human neutrophils. J Exp Med. 1983;158(4):1160-1177.

23. Chan ES, Montesinos MC, Fernandez P, et al. Adenosine A(2A) receptors play a role in the pathogenesis of hepatic cirrhosis. Br J Pharmacol. 2006;148(8):1144-1155.

24. Khan N, Abbas AM, Whang N, Balart LA, Bazzano LA, Kelly TN. Incidence of liver toxicity in inflammatory bowel disease patients treated with methotrexate: a meta-analysis of clinical trials. Inflamm Bowel Dis. 2012;18(2):359-367.

25. Strober BE, Menon K. Folate supplementation during methotrexate therapy for patients with psoriasis. J Am Acad Dermatol. 2005;53(4):652-659.

26. Singh JA. Folic acid supplementation for rheumatoid arthritis patients on methotrexate: the good gets better. Cochrane Database Syst Rev. 2013;(7):ED000063.

27. van Ede AE, Laan RF, Rood MJ, et al. Effect of folic or folinic acid supplementation on the toxicity and efficacy of methotrexate in rheumatoid arthritis: a forty-eight week, multicenter, randomized, double-blind, placebo-controlled study. Arthritis Rheum. 2001;44(7):1515-1524.

28. Whiting-O'Keefe QE, Fye KH, Sack KD. Methotrexate and histologic hepatic abnormalities: a meta-analysis. Am J Med. 1991;90(6):711-716. 
29. Aithal GP, Haugk B, Das S, Card T, Burt AD, Record CO. Monitoring methotrexate-induced hepatic fibrosis in patients with psoriasis: are serial liver biopsies justified? Aliment Pharmacol Ther. 2004;19(4):391-399.

30. van der Voort EA, Koehler EM, Nijsten T, et al. Increased prevalence of advanced liver fibrosis in patients with psoriasis: a cross-sectional analysis from the Rotterdam Study. Acta Derm Venereol. 2016;96(2):213-217.

31. Maybury CM, Jabbar-Lopez ZK, Wong T, Dhillon AP, Barker JN, Smith $\mathrm{CH}$. Methotrexate and liver fibrosis in people with psoriasis: a systematic review of observational studies. Br J Dermatol. 2014;171(1):17-29.

32. Roenigk HH Jr, Maibach HI, Weinstein GP. Methotrexate therapy for psoriasis. Guideline revisions. Arch Dermatol. 1973;108(1):35.

33. Berends MA, van Oijen MG, Snoek J, et al. Reliability of the Roenigk classification of liver damage after methotrexate treatment for psoriasis: a clinicopathologic study of 160 liver biopsy specimens. Arch Dermatol. 2007;143(12):1515-1519.

34. Montaudie H, Sbidian E, Paul C, et al. Methotrexate in psoriasis: a systematic review of treatment modalities, incidence, risk factors and monitoring of liver toxicity. J Eur Acad Dermatol Venereol. 2011;25(Suppl 2):12-18.

35. Langman G, Hall PM, Todd G. Role of non-alcoholic steatohepatitis in methotrexate-induced liver injury. $J$ Gastroenterol Hepatol. 2001;16(12):1395-1401.

36. Miele L, Vallone S, Cefalo C, et al. Prevalence, characteristics and severity of non-alcoholic fatty liver disease in patients with chronic plaque psoriasis. J Hepatol. 2009;51(4):778-786.

37. Rosenberg P, Urwitz H, Johannesson A, et al. Psoriasis patients with diabetes type 2 are at high risk of developing liver fibrosis during methotrexate treatment. J Hepatol. 2007;46(6):1111-1118.

38. Roenigk HH Jr, Auerbach R, Maibach H, Weinstein G, Lebwohl M. Methotrexate in psoriasis: consensus conference. JAm Acad Dermatol. 1998;38(3):478-485.

39. Kalb RE, Strober B, Weinstein G, Lebwohl M. Methotrexate and psoriasis: 2009 National Psoriasis Foundation Consensus Conference. $J$ Am Acad Dermatol. 2009;60(5):824-837.

40. Warren RB, Weatherhead SC, Smith CH, et al. British Association of Dermatologists' guidelines for the safe and effective prescribing of methotrexate for skin disease 2016. Br J Dermatol. 2016;175(1):23-44.

41. Houtman PM. [The practice guideline 'Photo(chemo)therapy and systemic therapy in severe chronic plaque-psoriasis']. Ned Tijdschr Geneeskd. 2005;149(1):54; author reply 54. Dutch.

42. Nast A, Gisondi P, Ormerod AD, et al. European S3-Guidelines on the systemic treatment of psoriasis vulgaris-Update 2015-Short version-EDF in cooperation with EADV and IPC. J Eur Acad Dermatol Venereol. 2015;29(12):2277-2294.

43. Nast A, Boehncke WH, Mrowietz U, et al. German S3-guidelines on the treatment of psoriasis vulgaris (short version). Arch Dermatol Res. 2012;304(2):87-113.

44. Aithal G. Hepatotoxicity Related to Methotrexate. In Kaplowitz N, DeLeve LD. Drug-induced Liver Disease. 3rd ed. London, UK, Walthan, MA and San Diego, CA: Elsevier 2013.

45. Lindsay K, Fraser AD, Layton A, Goodfield M, Gruss H, Gough A. Liver fibrosis in patients with psoriasis and psoriatic arthritis on long-term, high cumulative dose methotrexate therapy. Rheumatology (Oxford, England). 2009;48(5):569-572.

46. European Association for Study of Liver; Asociacion Latinoamericana para el Estudio del Higado. EASL-ALEH Clinical Practice Guidelines: non-invasive tests for evaluation of liver disease severity and prognosis. J Hepatol. 2015;63(1):237-264.

47. Castera L, Forns X, Alberti A. Non-invasive evaluation of liver fibrosis using transient elastography. J Hepatol. 2008;48(5):835-847.

48. Wong GL. Update of liver fibrosis and steatosis with transient elastography (Fibroscan). Gastroenterol Rep (Oxf). 2013;1(1):19-26.

49. Zelber-Sagi S, Yeshua H, Shlomai A, et al. Sampling variability of transient elastography according to probe location. Eur J Gastroenterol Hepatol. 2011;23(6):507-514.
50. Foucher J, Castéra L, Bernard PH, et al. Prevalence and factors associated with failure of liver stiffness measurement using FibroScan in a prospective study of 2114 examinations. Eur J Gastroenterol Hepatol. 2006;18(4):411-412.

51. Castera L, Foucher J, Bernard PH, et al. Pitfalls of liver stiffness measurement: a 5-year prospective study of 13,369 examinations. Hepatology. 2010;51(3):828-835.

52. Talwalkar JA, Kurtz DM, Schoenleber SJ, West CP, Montori VM. Ultrasound-based transient elastography for the detection of hepatic fibrosis: systematic review and meta-analysis. Clin Gastroenterol Hepatol. 2007;5(10):1214-1220.

53. Adebajo CO, Talwalkar JA, Poterucha JJ, Kim WR, Charlton MR. Ultrasound-based transient elastography for the detection of hepatic fibrosis in patients with recurrent hepatitis $\mathrm{C}$ virus after liver transplantation: a systematic review and meta-analysis. Liver Transpl. 2012;18(3):323-331.

54. Pavlov CS, Casazza G, Nikolova D, et al. Transient elastography for diagnosis of stages of hepatic fibrosis and cirrhosis in people with alcoholic liver disease. Cochrane Database Syst Rev. 2015;1:CD010542.

55. Pavlov CS, Casazza G, Nikolova D, Tsochatzis E, Gluud C. Systematic review with meta-analysis: diagnostic accuracy of transient elastography for staging of fibrosis in people with alcoholic liver disease. Aliment Pharmacol Ther. 2016;43(5):575-585.

56. National Institute for Health and Care Excellence. Non-alcoholic fatty liver disease (NAFLD): assessment and management (guideline NG49). 2016. Available from www.nice.org.uk/guidance/ng49. Accessed March $21,2018$.

57. National Institute for Health and Care Excellence: Guidance. Cirrhosis in Over 16s: Assessment and Management. (guideline NG49) 2016. Available from https://www.nice.org.uk/guidance/ng50. Accessed March 21, 2018.

58. Laharie D, Zerbib F, Adhoute X, et al. Diagnosis of liver fibrosis by transient elastography (FibroScan) and non-invasive methods in Crohn's disease patients treated with methotrexate. Aliment Pharmacol Ther. 2006;23(11):1621-1628.

59. Barbero-Villares A, Mendoza Jimenez-Ridruejo J, Taxonera C, et al. Evaluation of liver fibrosis by transient elastography (Fibroscan $\left.{ }^{\circledR}\right)$ in patients with inflammatory bowel disease treated with methotrexate: a multicentric trial. Scand J Gastroenterol. 2012;47(5):575-579.

60. Laharie D, Seneschal J, Schaeverbeke T, et al. Assessment of liver fibrosis with transient elastography and FibroTest in patients treated with methotrexate for chronic inflammatory diseases: a case-control study. J Hepatol. 2010;53(6):1035-1040.

61. Berends MA, Snoek J, de Jong EM, et al. Biochemical and biophysical assessment of MTX-induced liver fibrosis in psoriasis patients: Fibrotest predicts the presence and Fibroscan predicts the absence of significant liver fibrosis. Liver Int. 2007;27(5):639-645.

62. The Australasian College of Dermatologists 47th Annual Scientific Meeting, 18-21 May 2014, Melbourne, Victoria. Australas J Dermatol. 2014;55(Suppl 1):1-58.

63. Pongpit J, Porntharukchareon S, Kaewduang P, et al. Liver stiffness measurement in psoriasis: do metabolic or disease factors play the important role? Biomed Res Int. 2016;2016:7963972.

64. Bray AP, Barnova I, Przemioslo R, Kennedy CT. Liver fibrosis screening for patients with psoriasis taking methotrexate: a cross-sectional study comparing transient elastography and liver biopsy. Br J Dermatol. 2012;166(5):1125-1127.

65. Rongngern $\mathrm{P}$, Chularojanamontri L, Wongpraparut C, et al. Diagnostic performance of transient elastography for detection of methotrexate-induced liver injury using Roenigk classification in Asian patients with psoriasis: a retrospective study. Arch Dermatol Res. 2017;309(5):403-408.

66. Lynch M, Higgins E, McCormick PA, et al. The use of transient elastography and FibroTest for monitoring hepatotoxicity in patients receiving methotrexate for psoriasis. JAMA Dermatol. 2014;150(8):856-862.

67. Talme T, Nikamo P, Rosenberg P, Stahle M. Transient elastography may improve detection of liver fibrosis in psoriasis patients treated with methotrexate. Acta Dermato Venereol. 2017;97(8):952-954. 
68. Mardini H, Record C. Detection assessment and monitoring of hepatic fibrosis: biochemistry or biopsy? Ann Clin Biochem. 2005;42(Pt 6):441-447.

69. Reese LT, Grisham JW, Aach RD, Eisen AZ. Effects of methotrexate on the liver in psoriasis. J Invest Dermatol. 1974;62(6):597-602.

70. Zachariae H, Kragballe K, Sogaard H. Methotrexate induced liver cirrhosis. Studies including serial liver biopsies during continued treatment. Br J Dermatol. 1980;102(4):407-412.

71. Robinson JK, Baughman RD, Auerbach R, Cimis RJ. Methotrexate hepatotoxicity in psoriasis. Consideration of liver biopsies at regular intervals. Arch Dermatol. 1980;116(4):413-415.

72. Lanse SB, Arnold GL, Gowans JD, Kaplan MM. Low incidence of hepatotoxicity associated with long-term, low-dose oral methotrexate in treatment of refractory psoriasis, psoriatic arthritis, and rheumatoid arthritis. An acceptable risk/benefit ratio. Digest Dis Sci. 1985;30(2): 104-109.

73. Mitchell D, Smith A, Rowan B, et al. Serum type III procollagen peptide, dynamic liver function tests and hepatic fibrosis in psoriatic patients receiving methotrexate. Br J Dermatol. 1990;122(1):1-7.

74. Themido R, Loureiro M, Pecegueiro M, Brandao M, Campos MC Methotrexate hepatotoxicity in psoriatic patients submitted to long-term therapy. Acta Dermato Venereol. 1992;72(5):361-364.
75. Van Dooren-Greebe RJ, Kuijpers AL, Mulder J, De Boo T, Van de Kerkhof PC. Methotrexate revisited: effects of long-term treatment in psoriasis. Br J Dermatol. 1994;130(2):204-210.

76. Boffa MJ, Chalmers RJ, Haboubi NY, Shomaf M, Mitchell DM. Sequential liver biopsies during long-term methotrexate treatment for psoriasis: a reappraisal. Br J Dermatol. 1995;133(5):774-778.

77. Malatjalian DA, Ross JB, Williams CN, Colwell SJ, Eastwood BJ. Methotrexate hepatotoxicity in psoriatics: report of 104 patients from Nova Scotia, with analysis of risks from obesity, diabetes and alcohol consumption during long term follow-up. Can J Gastroenterol. 1996;10(6):369-375.

78. Zachariae H, Heickendorff L, Sogaard H. The value of aminoterminal propeptide of type III procollagen in routine screening for methotrexate-induced liver fibrosis: a 10-year follow-up. Br J Dermatol. 2001;144(1):100-103.

79. Berends MA, Snoek J, de Jong EM, et al. Liver injury in long-term methotrexate treatment in psoriasis is relatively infrequent. Aliment Pharmacol Ther. 2006;24(5):805-811.

80. Maybury CM, Samarasekera E, Douiri A, Barker JN, Smith CH. Diagnostic accuracy of noninvasive markers of liver fibrosis in patients with psoriasis taking methotrexate: a systematic review and meta-analysis. Br J Dermatol. 2014;170(6):1237-1247.
Psoriasis: Targets and Therapy

\section{Publish your work in this journal}

Psoriasis: Targets and Therapy is international, peer-reviewed, open access journal focusing on psoriasis, nail psoriasis, psoriatic arthritis and related conditions, identification of therapeutic targets and the optimal use of integrated treatment interventions to achieve improved outcomes

\section{Dovepress}

and quality of life. Visit http://www.dovepress.com/testimonials.php to read real quotes from published authors. 